\title{
A New 4,5-Secofurancadinene from the Rhizome of
}

Curcuma kwangsiensis

\author{
Weifeng Dai $\odot$, Lianli Zhang $\oplus^{*}$, Yanfang Liu $\odot$ and Mi Zhang \\ Faculty of Life Science and Technology, University of Kunming University of Science and \\ Technology, Kunming 650500, China
}

(Received January 03, 2020; Revised February 04, 2020; Accepted February 05, 2020)

\begin{abstract}
The rhizome of Curcuma kwangsiensis S. G. Lee et C. F. Liang is a Traditional Chinese Medicine indexed in Chinese Pharmacopoeia. A new compound, 4,5-seco-pyrocurzerenone (1), was isolated from the species along with sixteen sesquiterpenoids (2-17). Their structures were elucidated based on the spectroscopic evidence, mainly including NMR and HRESIMS. All the compounds were reported for the first time from this species.
\end{abstract}

Keywords: Sesquiterpenoid; 4,5-secofurancadinene; Curcuma kwangsiensis. (C) 2020 ACG Publications. All rights reserved.

\section{Plant Source}

The rhizome of Curcuma kwangsiensis S. G. Lee et C. F. Liang was purchased from the Juhua Traditional Chinese Medicine Market, Kunming, China, on July, 2015, and identified by Prof. Shiming Guo, Yunnan Institute of Traditional Chinese Medicine and Material Medica, China. The voucher specimen (CK-2015-07) was deposited in the laboratory of Faculty of Life Science and Technology, Kunming University of Science and Technology.

\section{Previous Studies}

Curcuma kwangsiensis S. G. Lee et C. F. Liang belongs to the genus Curcuma, in which many plants were rich of diphenylheptanes and sesquiterpenoids [2,3]. However, the constituents in Curcuma kwangsiensis S. G. Lee et C. F. Liang are found to have more diphenylheptanes, but less sesquiterpenoids [4-9].

\section{Present Study}

The rhizome of Curcuma kwangsiensis S. G. Lee et C. F. Liang is one of three base source plants of Rhizoma Curcumae indexed in Chinese Pharmacopoeia (2015 edition) [1], which has good effects on treating blood stasis, amenorrhea, indigestion and abdominal distension. Currently, seventeen

*Corresponding author: E-Mail: mizhangkmust@126.com (M. Zhang), Phone +86-871-65920738. 
sesquiterpenoids (1-17) were isolated from the rhizome of Curcuma kwangsiensis S. G. Lee et C. F. Liang for the first time, including a new 4,5-secofurancadinene (1) (Figure 1).

The rhizome of Curcuma kwangsiensis S. G. Lee et C. F. Liang (10.6 kg) was extracted with $75 \%$ ethanol $\left(10 \mathrm{~L} \times 4 \mathrm{~h} \times 4\right.$ times) to obtain a residue (1036.0 g), which then was suspended in $\mathrm{H}_{2} \mathrm{O}$ ( $3 \mathrm{~L}$ ) and partitioned successively with petroleum ether (3 $\mathrm{L} \times 4$ times) and EtOAc (3 $\mathrm{L} \times 4$ times). The petroleum ether extract ( $98.6 \mathrm{~g}$ ) was subjected to a column of silica gel eluted with petroleum ether EtOAc (1:0 to 1:2 v/v) to obtain 4 fractions (PA-PD). Fr. PB (14.3 g) was subjected to a column of silica gel eluted with petroleum ether - EtOAc to afford sub-fractions, which were further purified by Sephadex LH-20 with $\mathrm{CHCl}_{3}-\mathrm{MeOH}$ (1:1), followed semi-preparative HPLC (Zorbax SB-C ${ }_{18}, 9.4 \mathrm{~mm}$ $\times 250 \mathrm{~mm}, 0.5 \mu \mathrm{m})$ with $\mathrm{MeOH}-\mathrm{H}_{2} \mathrm{O}$ to obtain $\mathbf{6}(0.9 \mathrm{mg}), 7(1.0 \mathrm{mg}), \mathbf{8}(1.0 \mathrm{mg}), \mathbf{9}(0.8 \mathrm{mg}), \mathbf{1 0}(1.0$ $\mathrm{mg})$ and $11(0.9 \mathrm{mg})$. Fr. PC $(9.5 \mathrm{~g})$ was also purified by a series of silica gel column (petroleum ether - EtOAc), Sephadex LH-20 $\left(\mathrm{CHCl}_{3}-\mathrm{MeOH}\right)$ and semi-preparative HPLC $\left(\mathrm{MeOH}-\mathrm{H}_{2} \mathrm{O}\right)$ to yield 12 $(1.0 \mathrm{mg}), \mathbf{1 3}(1.3 \mathrm{mg}), \mathbf{1 4}(12.2 \mathrm{mg}), \mathbf{1 5}(26.0 \mathrm{mg})$ and $\mathbf{1 6}(16.9 \mathrm{mg})$. Fr. PD (7.1 g) was separated by a silica gel column (petroleum ether - EtOAc), followed Sephadex $\mathrm{LH}-20\left(\mathrm{CHCl}_{3}-\mathrm{MeOH}\right)$ and semipreparative HPLC ( $\left.\mathrm{MeOH}-\mathrm{H}_{2} \mathrm{O}\right)$ to obtain $17(1.7 \mathrm{mg})$. The EtOAc extract $(938.6 \mathrm{~g})$ was also subjected to a column of silica gel eluted with petroleum ether - EtOAc (1:0 to 1:2 v/v) to obtain 12 fractions (EA-EL). Fr. EA (9.6 g) was purified by a series of silica gel column (petroleum ether EtOAc), Sephadex LH-20 $\left(\mathrm{CHCl}_{3}-\mathrm{MeOH}\right)$ and semi-preparative HPLC $\left(\mathrm{MeOH}-\mathrm{H}_{2} \mathrm{O}\right)$ to obtain $\mathbf{1}$ (1.8 mg), 2 (14.8 mg), 3 (3.1 mg), 4 (21.3 mg) and 5 (6.7 mg).

Compound 1: Yellow oil; ${ }^{1} \mathrm{H}$ NMR (600 MHz, $\left.\mathrm{CDCl}_{3}\right) \delta(\mathrm{ppm}): 2.22(3 \mathrm{H}, \mathrm{s}, \mathrm{H}-14), 2.40(3 \mathrm{H}, \mathrm{s}, \mathrm{H}-13)$, 2.45 (3H, s, H-15), 2.70 (2H, m, H-3), 3.28 (2H, m, H-2), 7.48 (1H, s, H-9), 7.49 (1H, s, H-12), 10.80 $(1 \mathrm{H}, \mathrm{s}, \mathrm{H}-5) ;{ }^{13} \mathrm{C}$ NMR $\left(150 \mathrm{MHz}, \mathrm{CDCl}_{3}\right) \delta(\mathrm{ppm}): 12.9\left(\mathrm{CH}_{3}, \mathrm{C}-13\right), 20.2\left(\mathrm{CH}_{3}, \mathrm{C}-15\right), 24.1\left(\mathrm{CH}_{2}, \mathrm{C}-\right.$ 2), $30.0\left(\mathrm{CH}_{3}, \mathrm{C}-14\right), 44.2\left(\mathrm{CH}_{2}, \mathrm{C}-3\right), 115.6$ (C, C-11), 118.3 (CH, C-9), 128.7 (C, C-7), 129.2 (C, C6), 134.1 (C, C-10), 137.0 (C, C-1), 144.3 (CH, C-12), 155.1 (C, C-8), 192.2 (ㄷO, C-5), 208.4 (C, C4); HRESIMS $m / z 267.0990[\mathrm{M}+\mathrm{Na}]^{+}$(calcd for $\left.\mathrm{C}_{15} \mathrm{H}_{16} \mathrm{O}_{3} \mathrm{Na}, 267.0997\right)$.
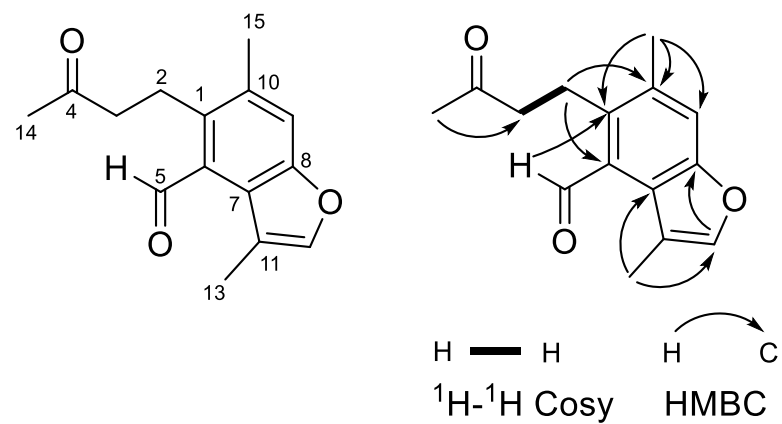

Figure 1. The structure and the key correlations in ${ }^{1} \mathrm{H}-{ }^{1} \mathrm{H}$ Cosy and $\mathrm{HMBC}$ of compound 1

Compound 1 was isolated as a yellow oil, whose molecular formula was determined as $\mathrm{C}_{15} \mathrm{H}_{16} \mathrm{O}_{3}$ by HRESIMS $\left(\mathrm{m} / \mathrm{z} 267.0990[\mathrm{M}+\mathrm{Na}]^{+}\right.$, calcd 267.0997) with eight indices of hydrogen deficiency. In the ${ }^{1} \mathrm{H}$ NMR spectrum of $\mathbf{1}$, three methyl at $\delta_{\mathrm{H}} 2.22(3 \mathrm{H}, \mathrm{s}), 2.40(3 \mathrm{H}, \mathrm{s})$ and $2.45(3 \mathrm{H}, \mathrm{s})$, two methylene at $\delta_{\mathrm{H}} 2.71(2 \mathrm{H}, \mathrm{m})$ and $3.28(2 \mathrm{H}, \mathrm{m})$, two olefinic methine at $\delta_{\mathrm{H}} 7.48(1 \mathrm{H}, \mathrm{s})$ and $7.49(1 \mathrm{H}$, $\mathrm{s})$, and one aldehydic proton at $\delta_{\mathrm{H}} 10.80(1 \mathrm{H}, \mathrm{s})$ were shown, which were further assigned to the corresponding carbons at $\delta_{\mathrm{C}} 30.0$ (C-14), 12.9 (C-13), 20.2 (C-15), 44.2 (C-3), 24.1 (C-2), 118.3 (C-9), 144.3 (C-12), and 192.2 (C-5), according to ${ }^{13} \mathrm{C}$ NMR, DEPT and HSQC spectra. Except those eight assigned carbon signals, other seven quaternary carbons were shown in the downfield of ${ }^{13} \mathrm{C}$ NMR, including six olefinic $\left(\delta_{\mathrm{C}} 115.6,128.7,129.2,134.1,137.0,155.1\right)$ and a ketocarbonyl $\left(\delta_{\mathrm{C}} 208.4\right)$, which were also supported by the DEPT and HSQC spectra. In HMBC spectrum, the correlations from Me-14 to C-3, and from H-5 to C-1 and 7 indicated 1 contains one formyl and one acetyl located in C3 and C-6, respectively. Other correlations from Me-13 to C-7, 11 and 12, Me-15 to C-1, 9 and 10 observed in $\mathrm{HMBC}$, together with the eight indices of hydrogen deficiency, further suggested $\mathbf{1}$ was a furancadinene, structurally similar with pyrocurzerenone (4) [12], except two more carbonyl carbons 
$\left(\delta_{\mathrm{C}} 192.2,208.4\right)$ presented in compound 1, instead of one olefinic secondary and one olefinic quaternary carbons in pyrocurzerenone (4). These evidence also revealed the olefinic bond in C-4 and -5 in pyrocurzerenone (4) was oxidized and transformed into one formyl and one acetyl in compound 1 (Figure 1). Thus,compound 1 was named as 4,5-seco-pyrocurzerenone.

The sixteen known sesquiterpenes were identified as ( \pm )-commyrrin A (2) [10], furanocadalene (3) [11], pyrocurzerenone (4) [12], 4,10-E-pizedoarondiol (5) [13], procurcumadiol (6) [14], doarondiol (7) [14], sozedoarondiol (8) [15], $(1 S, 4 S, 5 S, 10 R)$-zedoarondiol (9) [16], aerugidiol (10) [16], curzereone (11) [17], isoprocurcumenol (12) [16], zedoalactone F (13) [18], zederone (14) [19], $1 \alpha, 4 \beta$-dihydroxyeudesman-8-one (15) [20], germacrone (16) [13], and procurcumadiol (17) [21] by comparing their NMR and MS date with those reported in the literature. All of them were found in this plant for the first time.

\section{Acknowledgments}

This work was supported by the the National Natural Science Fund (31500287).

\section{Supporting Information}

Supporting Information accompanies this paper on http://www.acgpubs.org/journal/recordsof-natural-products

\section{ORCID}

Weifeng Dai: 0000-0003-1148-5907

Lianli Zhang: 0000-0001-7335-4633

Yanfang Liu: 0000-0002-6614-7449

Mi Zhang: 0000-0001-6410-6128

\section{References}

[1] State Pharmacopoeia Committee. Chinese Pharmacopoeia, Part 1 (2015). Beijing: China Medical Science and Technology Press, 208.

[2] W. Zhao, C. Wu, S. Guo, H. Gao, H. Tao, J. Lu, Y. Wang and X. Chen (2017). Chemical constituents and biological research on plants in the genus Curcuma, Crit. Rev. Food Sci. Nutr. 57, 1451-1523.

[3] A. Afzal, G. Oriqat, M. A. Khan, J. Jose and M. Afzal (2013). Chemistry and biochemistry of terpenoids from Curcuma and related species, J. Biologic. Ac. Prod. Nat. 3, 1-55.

[4] M. G. Phan, T. T. N. Tran, T. S. Phan, K. Matsunami and H. Otsuka (2014). Guaianolides from Curcuma kwangsiensis, Phytochemistry Lett. 9, 137-140.

[5] F. F. Xiang, J. W. He, Z. X. Liu, Q. Z. Peng and H. Wei (2018). Two new guaiane-type sesquiterpenes from Curcuma kwangsiensis, and their inhibitory activity of nitric oxide production in lipopolysaccharide-stimulated macrophages, Nat. Prod. Res. 32, 2670-2675.

[6] J. Li, Y. Liu, J. Q. Li, L. X. Chen, F. Zhao and F. Qiu (2011). Chemical constituents from the rhizomes of Curcuma kwangsiensis, Chin. J. Nat. Med. 9, 329-333.

[7] J. T. Wang, D. Ge, H. F. Qu, G. K. Wang and G. Wang (2019). Chemical constituents of Curcuma kwangsiensis and their antimigratory activities in RKO cells, Nat. Prod. Res. 33, 3493-3499.

[8] J. Li, F. Zhao, M. Z. Li, L. X. Chen and F. Qiu (2010). Diarylheptanoids from the rhizomes of Curcuma kwangsiensis, J. Nat. Prod. 73, 1667-1671.

[9] S. D. Chen, J. T. Gao, J. G. Liu, B. Liu, R. Z. Zhao and C. J. Lu (2015). Five new diarylheptanoids from the rhizomes of Curcuma kwangsiensis and their antiproliferative activity, Fitoterapia 102, 67-73.

[10] Y. Ge and J. L. Zhang (2018). Bioactive sesquiterpenoids and steroids from the resinous exudates of Commiphora myrrha, Nat. Prod. Res. https://doi.org/10.1080/14786419.2018.1448811.

[11] C. Murakami, J. H. G. Lago, F. F. Perazzo, K. S. Ferreira, M. E. L. Lima, P. R. H. Moreno and M. C. M. Young (2013). Chemical composition and antimicrobial activity of essential oils from Chromolaena laevigata during flowering and fruiting stages, Chem. Biodivers. 10, 621-627.

[12] H. Likino, K. Agatsuma, C. Konno and T. Takemoto (1968). Thermal rearrangement curzerenones, Tetrahedron Lett. 42, 4417-4419. 
[13] A. Saifudin, K. Tanaka, S. Kadota and Y. Tezuka (2013). Sesquiterpenes from the Rhizomes of Curcuma heyneana, J. Nat. Prod. 76, 223-229.

[14] H. J. Jang, J. H. Kim, H. M. Oh, M. S. Kim, J. H. Jo, K. Jung, S. Lee, Y. H. Kim, S. W. Lee and M. C. Rho (2016). Sesquiterpenoids from the rhizomes of Curcuma phaeocaulis and their inhibitory effects on LPSinduced TLR4 activation, Chem. Pharm. Bull. 64, 1062-1066.

[15] Y. W. Ge (2007). Studies on chemical constituents in Guiyujin, Northwest A\&F University.

[16] Y. Lou, F. Zhao, H. He, K. P. Peng, X. H. Zhou, L. X. Chen and F. Qiu (2009). Guaiane-type sesquiterpenes from Curcuma wenyujin and their inhibitory effects on nitric oxide production, J. Asian Nat. Prod. Res. 11, 737-747.

[17] A. Dekebo, E. Dagne and O. Sterner (2002). Furanosesquiterpenes from Commiphora sphaerocarpaand related adulterants of true myrrh, Fitoterapia 73, 48-55.

[18] M. Kuroyanagi, A. Ueno, K. Koyama and S. Natori (1990) Structures of sesquiterpenes of Curcuma aromatica Salisb. II. Studies on minor sesquiterpenes, Chem. Pharm. Bull. 38, 55-58.

[19] R. Chokchaisiri, P. Pimkaew, P. Piyachaturawat, R. Chalermglin and A. Suksamrarn (2014). Cytotoxic sesquiterpenoids and diarylheptanoids from the rhizomes of Curcuma elata Roxb(J). Rec. Nat. Prod. 8, 46-50.

[20] T. H. Quang, D. S. Lee, Y. Kim, H. Oh, H. Beak and Y. C. Kim (2014). A new germacrane-type sesquiterpene from fermented Curcuma longa L, Bull. Korean Chem. Soc. 35, 2201-2204.

[21] P. M. Giang, P. T. Son, K. Matsunami and H. Otsuka (2012). One new and several minor diarylheptanoids from Amomum muricarpum, Nat. Prod. Res. 26, 1195-1200.

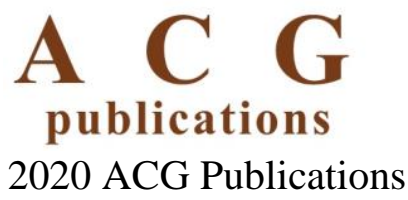

